\title{
Physicochemical characteristics of organophilic clays prepared using two organo-modifiers: alkylammonium cation arrangement models
}

\author{
Ismail Ltifi ${ }^{1}$. Fadhila Ayari ${ }^{1}$ - Dalila Ben Hassen Chehimi ${ }^{1} \cdot$ Malika Trabelsi Ayadi $^{1}$
}

Received: 25 November 2017 / Accepted: 21 May 2018 / Published online: 30 May 2018

(c) The Author(s) 2018

\begin{abstract}
The clay was modified by an ion exchange reaction with cetylpyridinium chloride CPC and hexadecyltrimethylammonium bromide HDTMA. The modified samples were studied by X-ray diffraction (XRD), Fourier transform infrared spectroscopy (FTIR) and scanning electron microscopy (SEM). The basal spacing of unmodified clay determined by XRD was $12.72 \AA$ and, after modification, increased with increasing concentration; expressed as a function of the cation exchange capacity (CEC) of the clay; to reach 21.08 and $26 \AA$ for clays modified with CPC and HDTMA successively for an equal concentration of 3CEC. FTIR studies revealed structural differences between modified and unmodified clay samples. Modified clay spectra showed C-N functional bands $\left(1480 \mathrm{~cm}^{-1}\right.$ ) and C-H vibrations (near 2936 and $2871 \mathrm{~cm}^{-1}$ ). The results of the SEM study reveal a difference between natural and modified clays. The purified clay has massive and curved plates. However, the modified clays show numerous small aggregate particles and plaques that become relatively flat. The arrangement of surfactants in clay is rather complicated. It depends on the nature of the surfactant molecules, the CEC of the clay and the method of preparation. According to these parameters, the inserted surfactants may be arranged in monolayer, paraffinic or admicelles structures.
\end{abstract}

Keywords Tunisian clay $\cdot$ HDTMA $\cdot$ HDPyridine $\cdot$ Arrangements

\section{Introduction}

There has been growing interest in the development of innovative adsorbent materials to solve the problem of industrial wastewater pollution (Nejib et al. 2014; Ltifi et al. 2017; Nahed and Kais 2015). Natural clays are considered among the available materials such as montmorillonite which is widely used as adsorbents because of the high cation exchange capacity (CEC), so that their swelling properties are high (Ayari et al. 2005). Montmorillonite (MMT) is a 2:1 clay mineral that has two silica-oxygen tetrahedral sheets with a central alumina octahedral layer (TOT layer).

Mixed "clay-surfactant" systems are of great interest for industrial applications. Nowadays, they are used in various fields as thickeners in inks, in the preparation of nanoparticle

Ismail Ltifi

ltifi.ismail@gmail.com

1 Laboratory for the Application of Chemistry to Natural Resources and Substances and the Environment (LACReSNE), Faculty of Sciences Bizerte, University Carthage, Tunis, Tunisia silver also as additives thickeners and in cosmetic formulations, as sorbents of organic compounds present (dyes, metals heavy) wastewater. Their main interest comes from the properties conferred by the intercalation of organic cations in interfolliairy clay space. Substitution of surfactants greatly increases the hydrophobicity of interfolliairy clay space, and therefore, clay can be swollen in non-aqueous systems. The adsorption of alkylammonium molecules or cations on the clay has different structures depending on the cation exchange capacity of clay (CEC), the size of the alkyl chain or the method of preparation. These molecules or cations can adopt various arrangements in the interlayer spacing of the clay.

The hexadecyltrimethylammonium bromide HDTMA intercalated in Na-montmorillonite has a paraffin-type monolayer arrangement parallel to the basal montmorillonite spacing. With the increase in the concentration of surfactants hexadecyltrimethylammonium bromide and cetylpyridinium chloride (0-3 CEC) in montmorillonite (Tahani et al. 1999), the adsorption of the cationic surfactant has been widely studied for several types of clay such as montmorillonite 
(Zhu et al. 2003), saponite (Ogawa et al. 1995), kaolinite (Komoria et al. 1999) and mica (Chen et al. 1992).

In contrast, few articles are devoted to the adsorption of organic ammonium cations on natural interstratified clays composed of smectite, kaolinite and illite.

The aim of the present study is to try to elucidate the mechanism by which surfactant molecules or cations are intercalated in the interlayer space of these clays, thanks to an analysis based on adsorption isotherms, spectroscopy FTIR and diffraction of rays X.

\section{Experimental}

\section{Materials}

The clay used is from the GAFSA region located south of 'TUNISIA.' Organic surfactants used were hexadecyltrimethylammonium bromide (HDTMA, formula weight: 364.45 and chemical formula: $\mathrm{C}_{19} \mathrm{H}_{42} \mathrm{BrN}$ ) and cetylpyridinium chloride (CPC, formula weight: 339.9 and chemical formula: $\mathrm{C}_{21} \mathrm{H}_{38} \mathrm{ClN}$ ) was obtained from Sigma-Aldrich. The molecular structure of CPC and HDTMA is illustrated in (Fig. 1). Other chemical reagents, such as $\mathrm{NaOH}, \mathrm{HCl}$ and $\mathrm{AgNO}_{3}$, were utilized of analytical grade.

\section{Preparation of organoclays}

The organophilic clays are prepared by the procedure which takes place in two stages; on the one hand, a $20 \mathrm{~g}$ of the adsorbent (Gafsa Clay) is dispersed in about $500 \mathrm{ml}$ of water in distilled water. On the other hand, a desired amount of surfactant (HDTMA or CPC) was stirred in $100 \mathrm{ml}$ of distilled water until it was completely dissolved and then added drop wise to the clay solutions. The amounts of each surfactant were calculated on the basis of the CEC of the adsorbent. The reaction mixtures were mechanically stirred

\begin{tabular}{|c|c|}
\hline Molecules & Molecular structure \\
\hline $\begin{array}{c}\text { Hexadecyltrimethylammonium } \\
\text { bromide } \\
\text { HDTMA } \\
\mathrm{C}_{19} \mathrm{H}_{42} \mathrm{BrN}\end{array}$ & 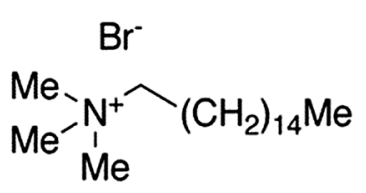 \\
\hline $\begin{array}{c}\text { Cetylpyridinium chloride } \\
\text { CPC } \\
\mathrm{C}_{21} \mathrm{H}_{38} \mathrm{CIN}\end{array}$ & $\begin{array}{l}11 \\
\mathrm{Cl}_{+}^{-} \\
\mathrm{CH}_{+} \\
\mathrm{CH}_{2}\left(\mathrm{CH}_{2}\right)_{14} \mathrm{CH}_{3}\end{array}$ \\
\hline
\end{tabular}

Fig. 1 Molecular structure of HDTMA, and CPC at room temperature for $48 \mathrm{~h}$. The resulting mixture was filtered through filter papers and washed with distilled water until complete breakdown of $\mathrm{Br}^{-}$and $\mathrm{Cl}^{-}\left(\mathrm{AgNO}_{3}\right.$ test). The products are dried at $80{ }^{\circ} \mathrm{C}$ for $12 \mathrm{~h}$. Finally, the adsorbents were ground in an agate mortar and stored (Ltifi et al. 2017).

\section{Characterization methods}

The prepared organoclays were characterized by X-ray diffraction (XRD), surface area measurement (BET), Fourier transform infrared spectroscopy (FTIR). XRD for obtaining basal spacing $d(001)$ values was operated, and the method was described in the paper by Park et al. (2013). The mineralogical composition was determined in the $<2 \mu \mathrm{m}$ fraction. The proportions of species in clay were estimated by the refence intensity ratio method using the High Score software. The specific surface area $\left(S_{\mathrm{s}}\right)$ measured by the BET and the cation exchange capacity (CEC) is determined by the method of MANTIN (Mantin 1969). The zero charge point (PZNPC) of the aqueous clay adsorbent was analyzed using the solid addition method (Wibowo et al. 2007).

\section{Characterization}

\section{X-ray diffraction}

$\mathrm{X}$-ray diffraction (XRD) patterns were recorded using $\mathrm{Cu}$ $K \alpha$ radiation $(n=1.5418 \AA$ ), a Philips PANalytical X' Pert PRO diffractometer operating at $40 \mathrm{kV}$ and $40 \mathrm{~mA}$ with $0.25^{\circ}$ divergence slit. For XRD at low angle section, it was between $1^{\circ}$ and $30^{\circ}(2 \theta)$ at a step size of $0.0167^{\circ}$ with variable divergence slit and $0.125^{\circ}$ anti-scatter slit.

\section{Spectroscopy IR}

Infrared spectra are collected on PERKIN ELMER 66 (Fourier transform infrared spectrometer); OPUS software allows the band intensity to be normalized by the most intense one. Spectra are collected over the spectral range $400-4000 \mathrm{~cm}^{-1}$.

\section{Measurement of the specific surface by the BET method and cation exchange capacity (CEC)}

Nitrogen adsorption measurements were performed at $77 \mathrm{~K}$ with an Autosorb-1 unit (Quantachrome) for the determination of sample textural properties using the multipoint Brunauer-Emmett-Teller (BET) method. The samples were out gassed at $120{ }^{\circ} \mathrm{C}$ under a vacuum at $10-3 \mathrm{~mm} \mathrm{Hg}$ for $3.5 \mathrm{~h}$.

CEC was determined by adsorption of copper ethylenediamine (EDA) ${ }_{2} \mathrm{CuCl}_{2}$ complex (Bergaya and Vayer 1997). 


\section{Morphology MEB}

The morphology of the prepared materials was evaluated by transmission electron microscopy (TEM); the SEM images were taken by a Hitachi S-3400N transmission electron microscopy.

\section{Results and discussion}

\section{Chemical composition of raw and purified clay}

The results of the chemical analysis given in Table 1 show:

- Silica/alumina ratios equal to 3.14 characteristics of montmorillonite. Value included in the domain $(2.5,5)$.

- A high content of magnesium and iron.

- The clay phase consists mainly of montmorillonite with a small amount of illite and kaolinite.

The silica to alumina $\mathrm{SiO}_{2} / \mathrm{Al}_{2} \mathrm{O}_{3}$ ratio confirms montmorillonite and the essential component of GAFSA clay. These results show a decrease in the silica content $\left(\mathrm{SiO}_{2}\right)$ from $54.3 \%$ for the crude clay to $47.51 \%$ for the purified clay and sodium.

The decrease in the $\mathrm{CaO}$ and $\mathrm{MgO}$ content is due to the $\mathrm{Ca}$ and $\mathrm{Mg}$ cations exchanged by the sodium cations. In parallel during the treatment of the clay purified by sodium chloride $(\mathrm{NaCl})$ during the washing operations, there is an increase in the concentration of $\mathrm{Na}_{2} \mathrm{O}$. This increase is due to the ion exchange between the ions of the clay and the sodium ion from the salt $(\mathrm{NaCl})$.

Table 1 Chemical composition of the catalyst

\begin{tabular}{|c|c|c|}
\hline \multirow[t]{2}{*}{ Oxide elements (\%) } & \multicolumn{2}{|c|}{$\begin{array}{l}\text { Mass composition in \% cal- } \\
\text { cined clay oxides }\end{array}$} \\
\hline & ArB & ArP \\
\hline $\mathrm{SiO}_{2}$ & 54.30 & 47.51 \\
\hline $\mathrm{AI}_{2} \mathrm{O}_{3}$ & 16.42 & 15.13 \\
\hline $\mathrm{Fe}_{2} \mathrm{O}_{3}$ & 08.21 & 09.58 \\
\hline $\mathrm{MgO}$ & 04.75 & 03.47 \\
\hline $\mathrm{CaO}$ & 04.61 & 03.38 \\
\hline $\mathrm{K}_{2} \mathrm{O}$ & 01.32 & 00.96 \\
\hline $\mathrm{Na}_{2} \mathrm{O}$ & 00.75 & 06.34 \\
\hline Total & 90.38 & 86.37 \\
\hline $\mathrm{PF}$ & 10.40 & 11.20 \\
\hline $\mathrm{SiO}_{2} / \mathrm{Al}_{2} \mathrm{O}_{3}$ & 03.30 & 03.14 \\
\hline
\end{tabular}

Changes in basal spacings by organophilization

One of the most important methods for studying Interlayer displacement is X-ray diffraction (XRD). The decrease in the angle $2 \theta$ and the widening of the peak indicate an increase in interfolliairy spacing (Jahan et al. 2012). The Bragg law allows to calculate the distance of the silicate layer ( $n \lambda=2 d \sin \theta, d=$ interfolliairy distances). One of the most important properties of layered silicates is the distance between the clay layers $(d 001)$. This distance can be calculated with data collected from X-ray diffraction. It is also reflected in the XRD pattern of the purified clay. When the modification of substances cannot penetrate the interlayer space, the value of $d 001$ does not change (Kozak and Domka 2004), in our study and after the ion exchange reaction, the basal spacing increases from $12.72^{\circ}$ to $26^{\circ}$ for HDTMA and $21.08^{\circ}$ for $\mathrm{CPC}$ indicating that both cationic surfactants have been intercalated successfully within clay (Fig. 2) (Hoidy et al. 2009).

\section{Infrared spectroscopy (IR)}

Based on the results of the XRD, it was possible to confirm that the exchange of HDTMA and CPC polycations with the $\mathrm{Na}^{+}$alkaline cations of the interfoliairy space is successful.

Two absorption bands at $726-780 \mathrm{~cm}^{-1}$ correspond to the mode of vibration of deformation out of the plane of the $\mathrm{CH}_{2}$ group (Vaia et al. 1994).

The group in the $950-1100 \mathrm{~cm}^{-1}$ region corresponds to the stretching vibration of the $\mathrm{Si}-\mathrm{O}$ groups (Xie et al. 2001).

As shown in Fig. 3, new peaks appear at $2939 \mathrm{~cm}^{-1}$; $2842 \mathrm{~cm}^{-1}$ for clay-CPC and at $2936 \mathrm{~cm}^{-1}$ and $2871 \mathrm{~cm}^{-1}$ for clay-HDTMA which correspond to asymmetric vibration $-\mathrm{CH}_{2}$ and symmetric stretching $-\mathrm{CH}_{2}$. These bands are absent in the IR spectrum of unmodified purified clay ( 0 CEC) which indicates the incorporation of surfactants into the organophilic clays.

Since the groups are very narrow, the variation in their intensity increases with the increase in the initial surfactant content, indicating the intercalation of a larger amount of surfactant in the studied clay with the increase in the initial amount of the surfactant.

As shown in Fig. 3, when the surfactants are sandwiched within the clays of the clays, a broad band at $1480 \mathrm{~cm}^{-1}$ indicating the presence of the functional group $\mathrm{C}-\mathrm{N}$ corresponds to the tertiary amine as described in literature (Zhu et al. 2005).

The smectite family has spectral hydration characteristics that have been attributed to adsorption of water on the external surfaces of the clay as well as internal regions. The property of these interlayer waters greatly depends on the level of moisture and the intercalated cation. 


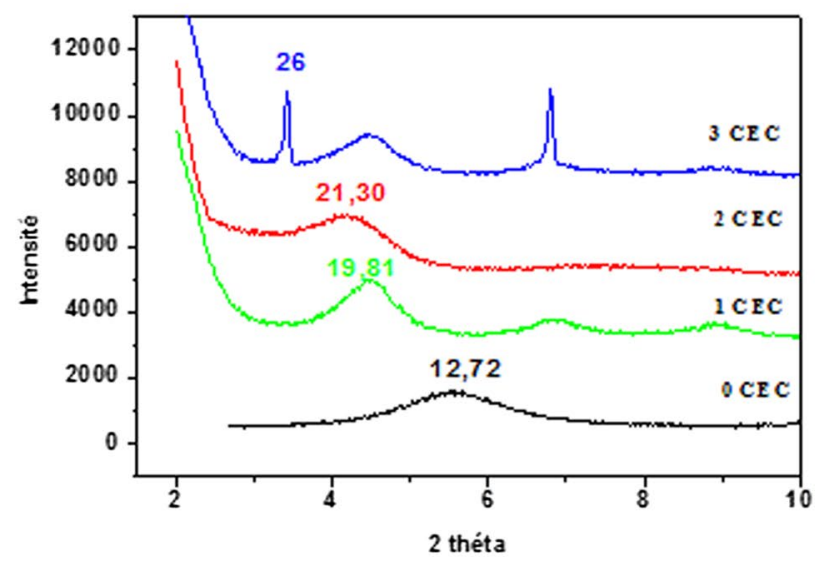

Modification Using HDTMA

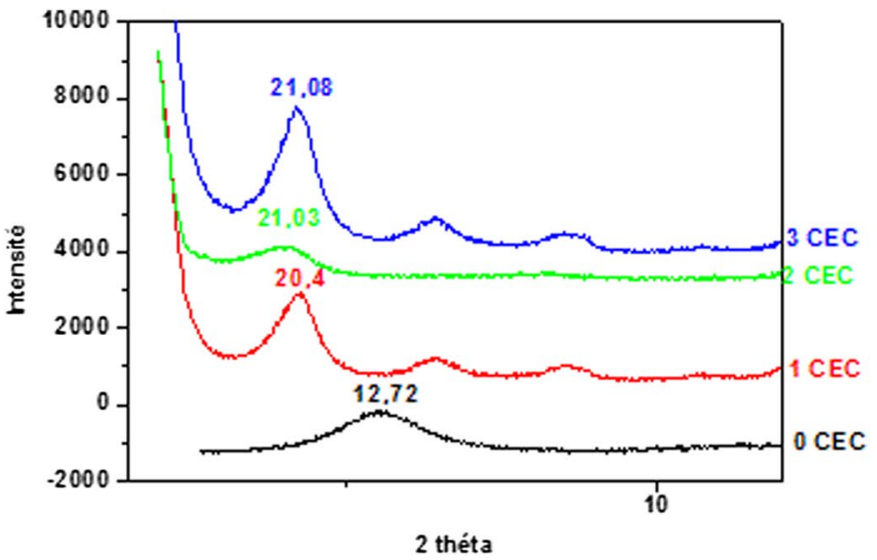

Modification Using CPC

Fig. 2 X-ray diffractograms of purified clay (0 CEC) and organophilic clays by HDTMA and CPC (different concentrations 1, 2 and 3 CEC)

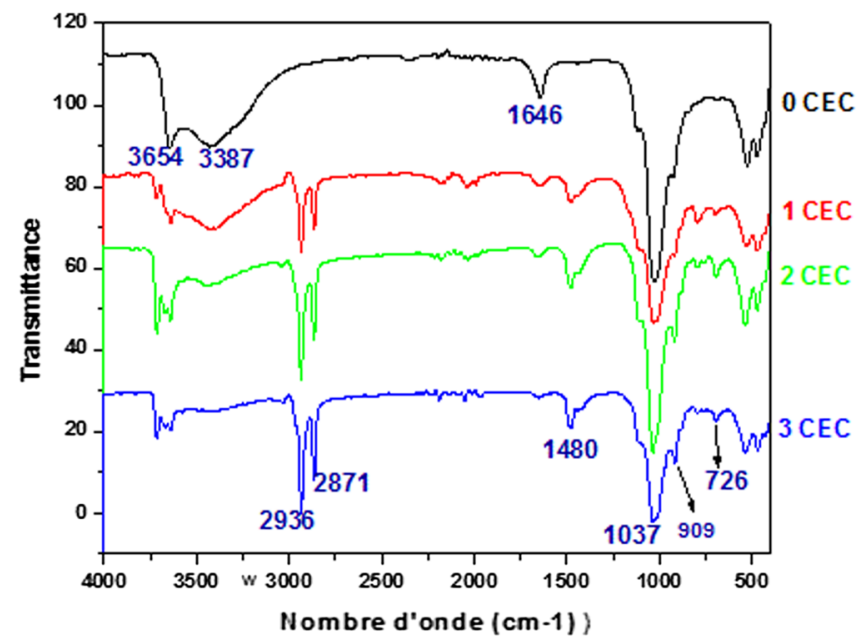

Modification Using HDTMA

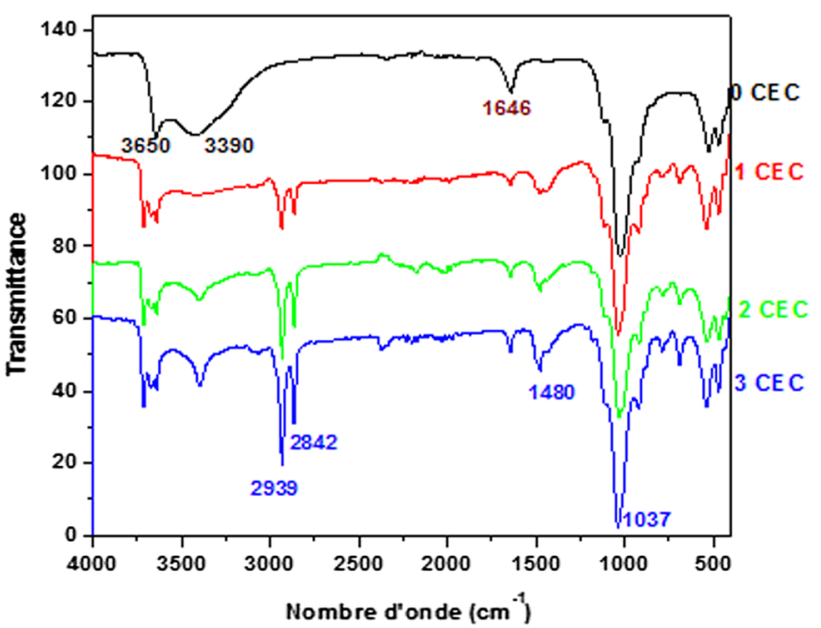

Modification Using CPC

Fig. 3 FTIR spectra of purified clay (0 CEC) and organophilic clays by HDTMA and CPC (different concentrations 1, 2 and 3 CEC)

The spectra show a more obvious adsorption band at $3620 \mathrm{~cm}^{-1}$ due to structural stretching vibrations of $\mathrm{OH}$ groups independent of surfactant loading which is consistent with the result indicated in the literature.

In the region between 3100 and $3500 \mathrm{~cm}^{-1}$, the spectra show a wide band around $3400 \mathrm{~cm}^{-1}$ corresponding to the symmetric and asymmetric overlapping of the vibrations (H-O-H).

When the surfactants are inserted in the smectite gallery, the adsorption bands detected are mainly attributed to the adsorbed water molecules, in particular with high surfactant loading. At the same time, with the intercalation of surfactants, the clay surface property is modified. As a result, the hydrophilic surface of the smectite has been changed and becomes hydrophobic and the clay becomes organophilic(Kung and Hayes 1993; Mandalia and Bergaya 2006).

\section{The study of the point of zero charge and cationic exchange capacity}

The PZNPC or $\mathrm{pH}$ zero corresponds to the $\mathrm{pH}$ value for which the net charge of the adsorbing surface is zero (Wibowo et al. 2007). This parameter is very important in the adsorption phenomena, especially when electrostatic forces are involved in the mechanisms. A quick and easy way to determine the PZNPC is to place $50 \mathrm{ml}$ of distilled water in closed bottles and adjust the $\mathrm{pH}$ of each (values between 2 


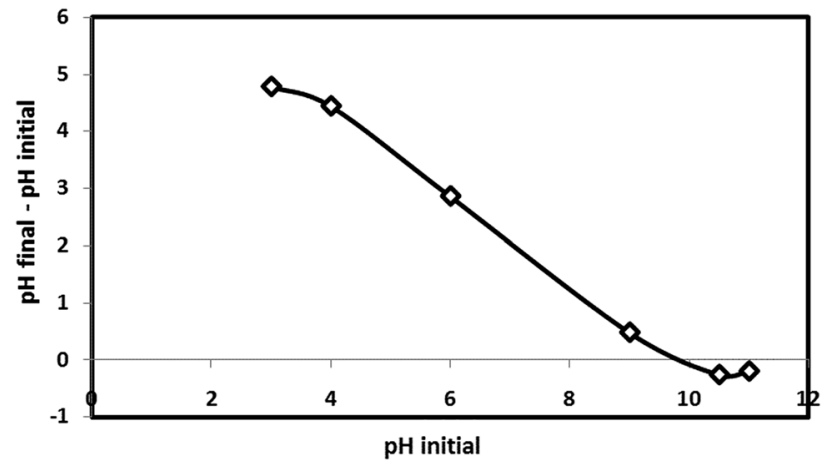

Fig. 4 Point of zero charge in clays

Table 2 The BET surface area, total pore volume and average pore diameter for clay, HDTMA-clay and CPC-clay

\begin{tabular}{lllll}
\hline Adsorbent samples & $S_{\text {BET }}\left(\mathrm{m}^{2} / \mathrm{g}\right)$ & $\mathrm{VP}\left(\mathrm{cm}^{2} / \mathrm{g}\right)$ & APD $(\mathrm{nm})$ & $d_{001}(\mathrm{~nm})$ \\
\hline Clay & 54.00 & 0.107 & 4.0 & 1.27 \\
HDTMA-clay & 02.19 & 0.011 & 3.3 & 2.60 \\
CPC-clay & 01.28 & 0.007 & 2.7 & 2.10 \\
\hline
\end{tabular}

$S_{B E T}$ specific surface area, $V P$ pore volume determined by $\mathrm{BJH}$ method from $\mathrm{N}_{2}$ desorption isotherm, $A P D$ average pore diameter determined by the curve of BJH desorption $\mathrm{d} V / \mathrm{d} D$ pore volume, $d_{001}$ Basal distance

and 12$)$ by addition of $\mathrm{NaOH}$ solution or $\mathrm{HCl}(0.1 \mathrm{M})$. Then added to each flask, $50 \mathrm{mg}$ of clay. The suspensions should be kept in agitation at room temperature for $24 \mathrm{~h}$, and the final $\mathrm{pH}$ is then determined. It relates to a graph $\mathrm{pH}=f\left(\mathrm{pH}_{\mathrm{i}}\right)$ where $\mathrm{pH}=\left(\mathrm{pH}_{\mathrm{f}}-\mathrm{pH}_{\mathrm{i}}\right)$; the intersection of the curve with the axis that passes through the zero gives the isoelectric point (Fig. 4).

Regarding the value of CEC of raw and purified clays, measurements of the cation exchange capacities of the studied clay are taken by the method of MANTIN.
It should be noted that for the raw sample, the CEC is $76 \mathrm{meq} / 100 \mathrm{~g}$ of calcined clay and that of the purified sample is $91.04 \mathrm{meq} / 100 \mathrm{~g}$ of calcined clay. This difference is due to the presence of impurities in the untreated sample, which are removed after purification.

The obtained CEC values are characteristic of smectite clay.

\section{BET analysis of clay and surfactant modified HDTMA and CPC}

Table 2 shows the BET surface area $\left(\mathrm{m}^{2} / \mathrm{g}\right)$, the total pore volume $\left(\mathrm{cm}^{3} / \mathrm{g}\right)$ and the average pore diameter $(\mathrm{nm})$ and the basal distance $\left(d_{001}\right)$ of the clay, clay-CPC adsorbent and clay-HDTMA. The BET surface area decreased from 54 to $1.28 \mathrm{~m}^{2} / \mathrm{g}$ for CPC-modified clay and to $2.19 \mathrm{~m}^{2} / \mathrm{g}$ for HDTMA-clay modification, which can be attributed to blockage and pore screening of clay by surfactant alkyl chains. The average pore diameter decreases slightly from 4.0 to $3.3 \mathrm{~nm}$ from clay to HDTMA-clay, which is likely due to the complete removal of micropores of the adsorbent structure (Gladysz-Plaska et al. 2012).

\section{Morphology and particle size by MEB}

The SEM micrographs (Fig. 5) show the surface morphology of montmorillonite and organophilic clay samples. It can be seen that the original montmorillonite Arg-Na has massive and curved plates (Fig. 5a) (Lee and Kim 2002). However, clay treated with cationic surfactants (HDTMA and HDPy) shows significant changes in morphology.

Compared to the morphology of Na-montmorillonite, there are many small aggregated particles and the plates become relatively flat in Arg-HDTMA and Arg-HDPy organophilic clays (Fig. 5b, c).

Therefore, the present study shows that not only the basal spacing but also the morphology of the organophilic clays
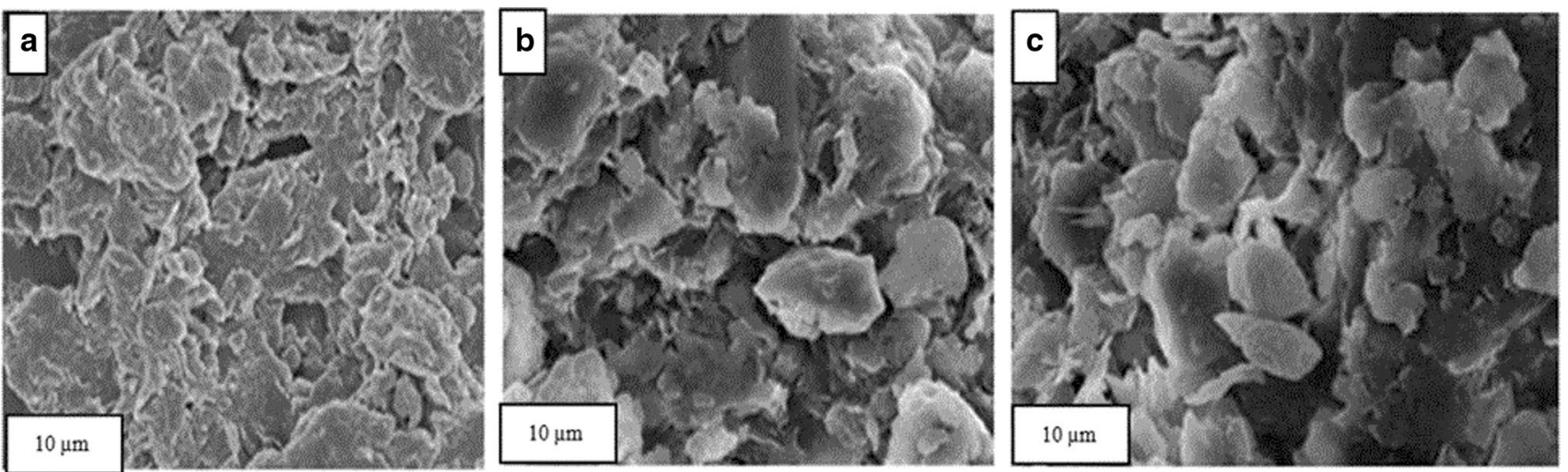

Fig. 5 SEM images of Arg-Na (a), Arg-HDTMA (b) and Arg-HDPy (c) 
strongly depends on the packing density of the surfactants in the interspace of montmorillonite.

\section{Alkyl chain arrangements}

Calculation of the angle of inclination:

According to Zhu et al. (2003), the theoretical length of the HDTMA cation is $25.3 \AA$, the height of the alkyl chain is $4.1 \AA$, and the head of the nail is $5.1 \AA$; The HDTMA cation is flat between layers of montmorillonite.

According to Gamoudi et al. (2015), the theoretical length of the cation HDPy is $23.1 \AA$, the height of the alkyl chain is $2.8 \AA$, and the head of the nail is $4.9 \AA$.

The difference between the values of the basal space $d 001$ affects the organization of the alkylammonium ions (HDTMA and HDPy) in the interfolliairy space, and the amount of surfactants also plays a role on the type of arrangement.

Based on the $d 001$ value and the dimensions of the alkylammonium, as shown in Fig. 6, the nature of the alkylammonium ion arrangements in the interfolliairy space is determined. All XRD analysis values of various organophilic clays are summarized in Table 3.

We also calculated the angle of inclination $(\alpha)$ of the alkylammonium ion between the clay sheets based on the interlayer distance $d 001$ and the length of the alkylammonium ion. These values were calculated assuming that the organization of ammonium ions is paraffinic.

It is important to note that the angle of inclination $(\alpha)$ of the alkylammonium ion between the clay layers is calculated as indicated by the following equation:

$\sin \alpha=\frac{d 001-e}{a}$
Fig. 6 Dimension of molecules (i) HDTMA+ and (ii) HDPy (Bors et al. 2001)
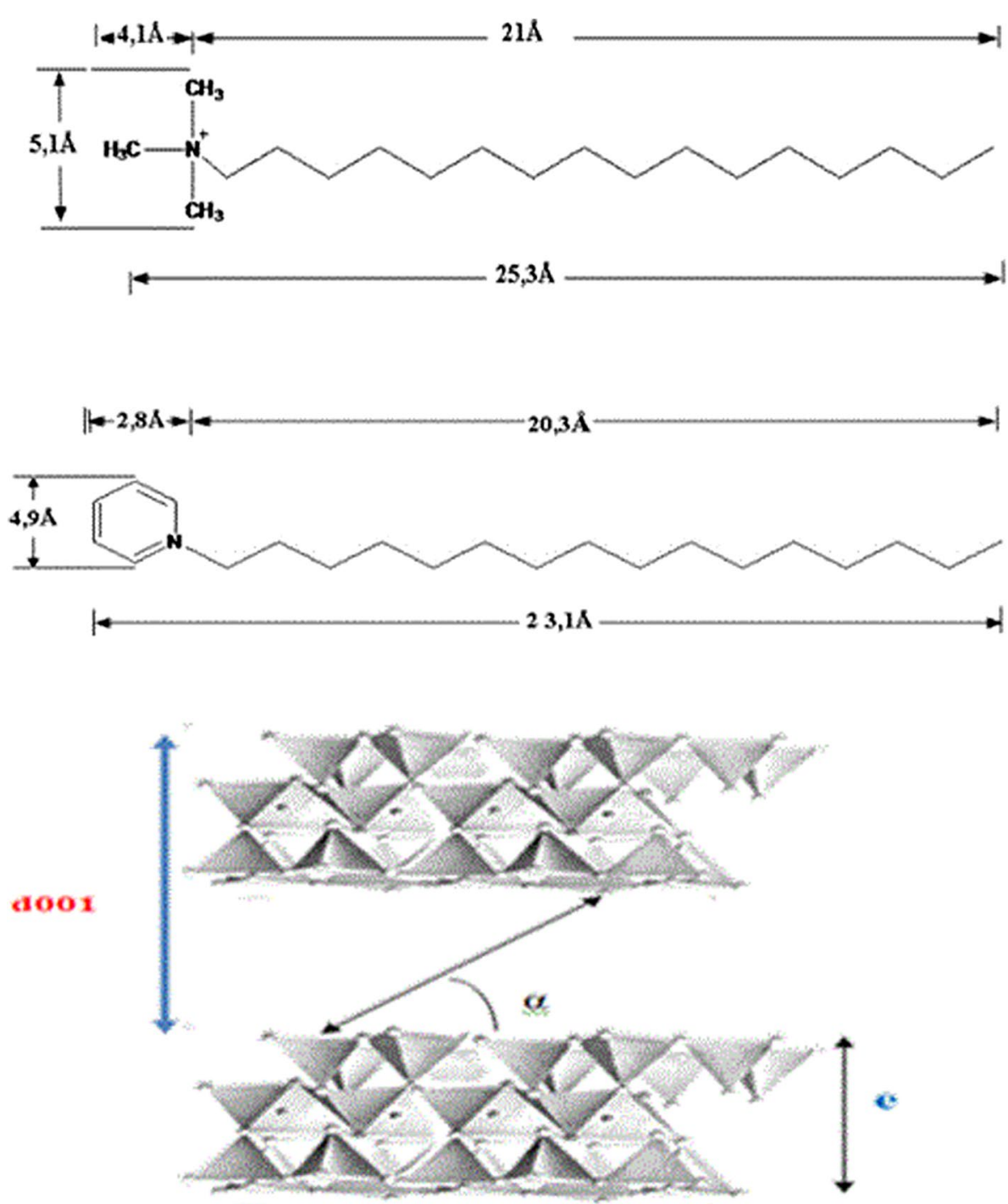
Table $3 d 001$ values of HDTMA, HDPy and different arrangements

\begin{tabular}{llllll}
\hline CEC & HDTMA & & & HDPyridine & \\
\cline { 2 - 3 } \cline { 5 - 6 } & $d / \mathrm{nm}$ & Arrangements & & $d / \mathrm{nm}$ & Arrangements \\
\hline 1 & $1.981(\alpha=35.45)$ & Paraffine-type monolayer & & $2.040(\alpha=42.06)$ & Paraffine-type monolayer \\
2 & $2.130(39.79)$ & Paraffine-type monolayer & & $2.103(\alpha=43.63)$ & Paraffine-type monolayer \\
3 & $2.600(\alpha=55.00)$ & Paraffine-type bilayer & & $2.108(\alpha=44.40)$ & Paraffine-type monolayer \\
\hline
\end{tabular}

$e$ thickness of the surfactant $(\AA) ; a$ length of the surfactant ( $\AA)$ (He et al. 2006).

For HDTMA: $e=5.1 \AA$ and $a=25.3 \AA$.

For HDPyridine: $e=4.9 \AA$ and $a=23.1 \AA$.

The spacing of organophilic clays increases with an increase in the amount of surfactant added (increase in the concentration of the alkylammonium salts).

The alkyl chains take the paraffin-type arrangement in the interfolliairy space of the clays. The angle of inclination $\alpha$ and the spacing $d$ increase with the increase in the concentration of the surfactants studied, as shown in Table 3.

In the case of HDTMA, for a concentration of 3CEC, the angle of inclination $\alpha$ is $55^{\circ}$. Under this condition, the alkyl chains take the arrangement of a paraffin-type bilayer in the studied clay, as illustrated in Fig. 7.

Likewise for HDPyridine and for the same concentration (3CEC), the alkyl chains adopt the paraffin-type single-layer structure. Therefore, the type of arrangement depends on the length of the alkyl chain as well as the concentration of surfactant.

\section{Conclusions}

In this study, modified organic clays were obtained with two different quaternary ammonium salts (HDTMA and HDPyridine). X-ray diffractograms show that the interlayer distance (d001) of the organophilic clay increases after treatment
Fig. 7 Representation of modified smectite arrangements by HDTMA (a) and HDPy (b). The lateral distances between the alkylammonium units are inversely related to the charge density of the layer
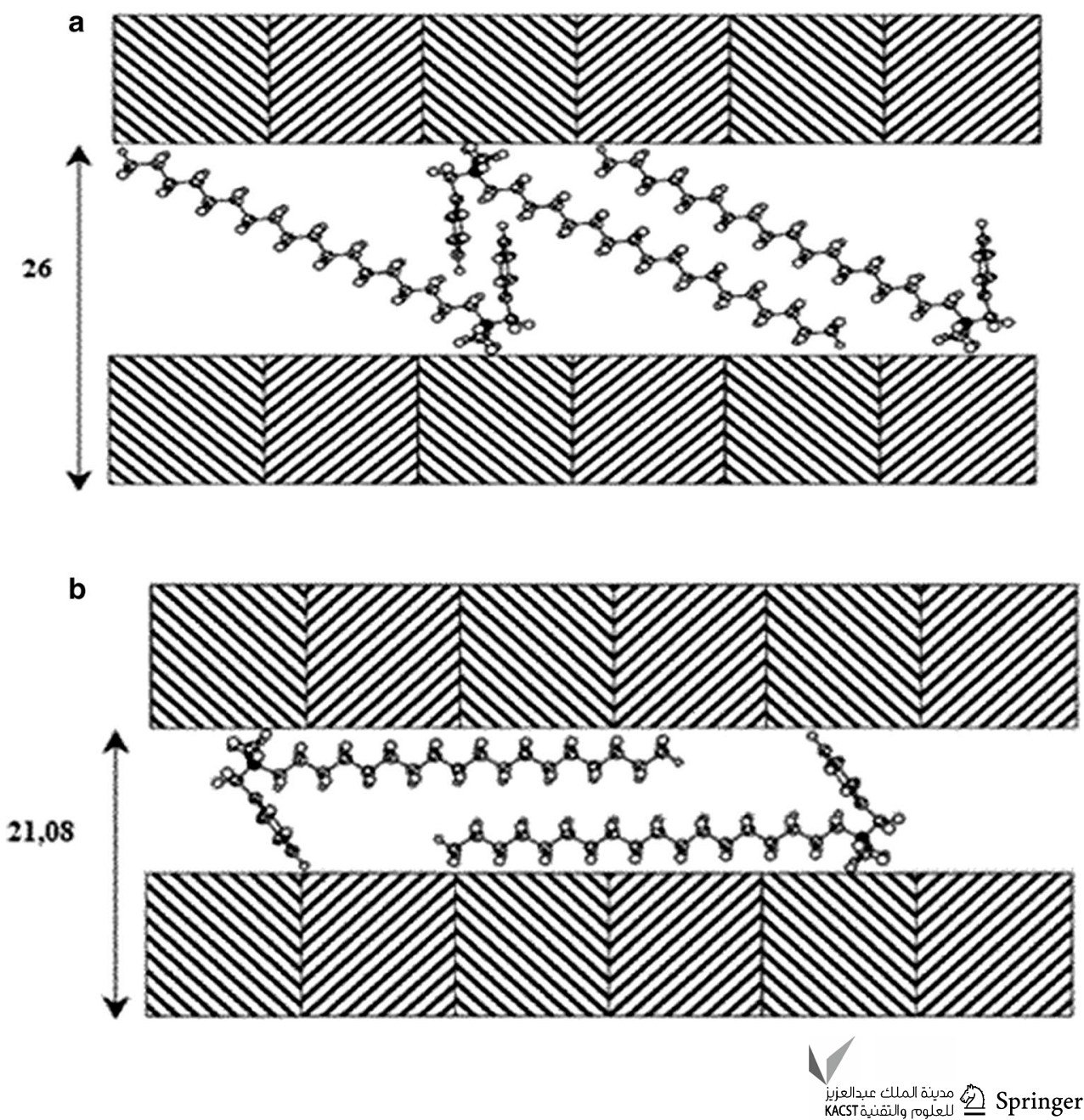
with the two quaternary ammonium salts (HDTMA and HDPyridine), confirming the intercalation of the ammonium cations within clay. The greatest interlayer distance is observed in clays treated with HDTMA salt. Infrared spectra showed new bands of vibrations $\mathrm{CH}_{2}$ and $\mathrm{CH}_{3}$, which correspond to the presence of ammonium salts inside the clay structure. Finally, the results of the adsorption capacity confirmed the great promise of using organophilic clays as adsorbents for the adsorption of organic solvents for the treatment of wastewater.

Open Access This article is distributed under the terms of the Creative Commons Attribution 4.0 International License (http://creativeco mmons.org/licenses/by/4.0/), which permits unrestricted use, distribution, and reproduction in any medium, provided you give appropriate credit to the original author(s) and the source, provide a link to the Creative Commons license, and indicate if changes were made.

\section{References}

Ayari F, Srasra E, Trabelsi-Ayadi M (2005) Characterization of bentonitic clays and their use as adsorbent. Desalination 185:391-397

Bergaya F, Vayer M (1997) CEC of clays: measurement by adsorption of a copper ethylenediamine complex. Appl Clay Sci 12:275-280

Bors J, Patzko A, Dekany I (2001) Adsorption behavior of radioiodides in hexadecylpyridinium-humate complexes. Appl Clay Sci 19:27-37

Chen YL, Chen S, Frank C, Israelachvili J (1992) Molecular mechanisms and kinetics during the self-assembly of surfactant layers. J Colloid Interface Sci 153:244-265

Gamoudi S, Frini-Srasra N, Srasra E (2015) Influence of synthesis method in preparation of HDTMA+- and HDPy+-illites/smectites. Appl Clay Sci 116-117:78-84

Gładysz-Płaska A, Majdan M, Pikus S, Sternik D (2012) Simultaneous adsorption of chromium (VI) and phenol on natural red clay modified by HDTMA. J Chem Eng 179:140-150

He HP, Frost RL, Bostrom T, Yuan P, Duong L, Yang D, Yunfel X (2006) Changes in the morphology of organoclays with HDTMA $^{+}$ surfactant loading. Appl Clay Sci 31:262-271

Hoidy WH, Ahmad MB, Mulla EA, Ibrahim NA (2009) Synthesis and characterization of organoclay from sodium montmorillonite and fatty hydroxamic acids. Am J Appl Sci 6:1567-1572

Jahan SA, Parveen S, Ahmed S, Kabir H (2012) Development and characterization of organophilic clay from bentonite. Mater Sci 8:67-72

Komoria Y, Sugahara Y, Kuroda K (1999) Intercalation of alkylamines and water into kaolinite with methanol kaolinite as an intermediate. Appl Clay Sci 15:241-252

Kozak M, Domka L (2004) Adsorption of the quaternary ammonium salts on montmorillonite. J Phys Chem Solids 65:441-445
Kung K, Hayes KF (1993) Fourier transform infrared spectroscopic study of the adsorption of cetyltrimethylammonium bromide and Cetylpyridinium chloride on silica. Langmuir 9:263-267

Lee SY, Kim SJ (2002) Expansion characteristics of organoclay as a precursor to nanocomposites. Colloids Surf A Physicochem Eng Asp 211:19-26

Ltifi I, Ayari F, Dalila BHC, Trabelsi-Ayadi M (2017) Study of the adsorption of bright green by a natural clay and modified. J Mater Sci Eng Omics 6:317-324

Mandalia T, Bergaya F (2006) Organoclay mineral-melted poly-olefin nanocomposites effect of surfactant/CEC ratio. J Phys Chem Solids 67:836-845

Mantin I (1969) Mesure de la capacité d'échange des minéraux argileux par l'éthylène diamine et les ions complexes de l'éthylène diamine. C R Sci Paris 269:815-818

Nahed N, Kais N (2015) Adsorption of textile dyes on raw Tunisian clay: equilibrium, kinetics and thermodynamics. J Adv Chem 11:6-19

Nejib A, Joëlle D, Abdellah E, Amane J, Trabelsi-Ayadi M (2014) Textile dye adsorption onto raw clay: influence of clay surface properties and dyeing additives. J Colloid Sci Biotechnol 3:98-110

Ogawa M, Wada T, Kuroda K (1995) Intercalation of pyrene into alkylammonium-exchanged swelling layered silicates: the effects of the arrangements of the interlayer alkylammonium ions on the states of adsorbates. Langmuir 11:4598-4600

Park Y, Frost R, Ayoko G, Morgan D (2013) Adsorption of p-nitrophenol on organoclays. J Therm Anal Calorim 111:41-47

Tahani A, Karroua M, Van Damme H, Levitz P, Bergaya F (1999) Adsorption of a cationic surfactant on Na-montmorillonite: inspection of adsorption layer by X-ray and fluorescence spectroscopies. J Colloid Interface Sci 216:242-249

Vaia RA, Teukolsky RK, Giannelis EP (1994) Interlayer structure and molecular environment of alkylammonium layered silicates. Chem Mater 6:1017-1022

Wibowo N, Setyadhi L, Wibowo D, Setiawan J, Ismadji S (2007) Adsorption of benzene and toluene from aqueous solution onto activated carbon and its acid heat treated forms: influence of surface chemistry on adsorption. J Hazard Mater 146:237-242

Xie W, Gao Z, Pan W-P, Doug H, Vaia R (2001) Thermal degradation chemistry of alkyl quaternary ammonium montmorillonite. Chem Mater 13:2979-2990

Zhu J, He X, Guo J, Yang G, Xie D (2003) Arrangement models of alkylammonium cations in the interlayer of HDTMA+ pillared montmorillonites. Chin Sci Bull 48:368-372

Zhu J, He H, Zhu L, Wen X, Deng F (2005) Characterization of organic phases in the interlayer of montmorillonite using FTIR and ${ }^{13} \mathrm{C}$ NMR. J Colloid Interface Sci 286:239-244

Publisher's Note Springer Nature remains neutral with regard to jurisdictional claims in published maps and institutional affiliations. 